\title{
Semantic processing in children 0 to 6 years of age: an $\mathrm{N} 400$ analysis
}

\author{
Tâmara Andrade Lindau ${ }^{(1,3)}$ \\ Célia Maria Giacheti ${ }^{(2,3)}$ \\ Isabella Bonamigo da Silva ${ }^{(2,3)}$ \\ Deisy das Graças de Souza ${ }^{(1,3)}$
}

(1) Universidade Federal de São Carlos - UFSCar, São Carlos, SP, Brazil.

(2) Universidade Estadual Paulista - UNESP, Marília, SP, Brazil.

(3) Instituto Nacional de Ciência e Tecnologia sobre Comportamento, Cognição e Ensino - INCT-ECCE - São Carlos/SP - Brazil.

Research support source: This research was part of the scientific program of Instituto Nacional de Ciência e Tecnologia sobre Comportamento, Cognição e Ensino, with support from the Brazilian National Research Council (CNPq, Grant \# 465686/2014-1) and the São Paulo Research Foundation (Grant \# 2014/50909-8). There was also support from CNPq (Grant \#141107/2015-4).

Conflict of interest: Nonexistent

Received on: August 24, 2017 Accepted on: September 13, 2017

Mailing address:

Tâmara Andrade Lindau

Av. Higyno Muzzi Filho, 737 - Marília,

São Paulo, Brasil

CEP: $17.525-900$

E-mail: lindau.andrade@gmail.com

\section{ABSTRACT}

This study consists of a literature review about the semantic processing in children 0 to 6 years of age and an N400 data analysis. Twenty-four studies that met the eligibility criteria were found. Most studies aimed to investigate and characterize the electrophysiological patterns of younger children as compared to those found in older children and adults. A large variability of employed experimental tasks was found, showing that there are various investigation alternatives in this perspective. In general, the joint analysis of the results pointed out that despite the different objectives, types of experimental tasks and degrees of language skills (i.e., typical development or different conditions), age was a relevant factor in establishing the presence or not of the N400 effect and its lateralization. When present, the N400 effect showed that the latency and amplitude of the wave decline according to age. However, the variability of procedures can affect the degree of control and the data reliability. For further studies, the development of a standard protocol to investigate the semantic processing by means of the N400 effect data in different populations is an important step and a strong recommendation for the area.

Keywords: Semantics; Evoked Potentials; Electrophysiology; Child; Review 


\section{INTRODUCTION}

Language is characterized as a dynamic and complex system which involves different types of information that are created according to the rules (e.g., syntactic, semantic, pragmatic, phonological subsystems) ${ }^{1,2}$. Although the integration of such subsystems is considered in order to understand a formal language definition, it is not completely clear how this integration happens at the language production and comprehension skills ${ }^{1,2}$.

Oral language comprehension is one of the skills of development and it involves different processing stages as the acoustic-phonological, the semantic primary (i.e., significant information activation of language) and the semantic secondary, in which the meaning of different words are associated in order to allow the comprehension in a specific context ${ }^{3-5}$.

In particular, neurophysiological techniques are used in order to investigate how the semantic processing occurs currently.

The electroencephalography (EEG) has been considered an important tool to investigate and identify the neural correlates of the cognitive behavior processes involved at the oral language regarding the contextual control6-8.

One of the electrophysiological measures provided by EGG is called Event-Related Potential (ERP) and it refers to small tensions/answers of the brain structures generated by different sensorial modalities stimuli (e.g., visual or auditory) which derivate regular patterns called components. Such components are classified under their polarity, negative $-\mathrm{N}-$ and positive $-\mathrm{P}-$ fluctuation, and latency after starting the stimulus (e.g., N100, N400, P600) $)^{9,10}$.

The N400 component - a negative wave that occurs between 250 and 500 milliseconds after starting the stimulus, and it peaks around $400 \mathrm{~ms}$ - was described for the first time in 1980 by Kutas and Hillyard ${ }^{11,12}$ while evaluating the reading of incongruous semantically words regarding the context of the sentence presented ${ }^{7}$. Currently, one can see that the N400 reflects at least two aspects: (1) the semantic integration to the context; (2) the access to information of the long term memory?. Several studies have investigated the $\mathrm{N} 400$ effect in children and adults ${ }^{2,7,13-15}$, and the overall finding indicates that the latency and amplitude of the wave decline over age $\mathrm{e}^{12-16}$ and that some factors - the frequency of the words, the context and the position of the word in the sentence - can influence the amplitude of the $\mathrm{N} 400$ effect $^{8}$.
Friedrich and Friederici $(2010)^{5}$ have proposed that the $\mathrm{N} 400$ effect provides clues about the relation between the language development and neural representations/functions that support its processing. Therefore, this effect can be used as methodological tool to study specific aspects of language development, because it subsidizes the investigation of subtle differences in the information processing that cannot be detected by means of behavioral measures both in typical and risk or communication disorder populations ${ }^{8-17}$.

The N400 effect enables us to address psycholinguistics issues in different stages of development, which are not feasible to be analyzed by other types of measurements ${ }^{8}$. The present study had the objective of submitting a bibliographic review about the semantic processing in children 0 to 6 years of age by analyzing the N400 data.

\section{METHODS}

This study is characterized by an integrative review of the specialized literature. The following steps have been considered on its elaboration: (1) identification of the topic; (2) establishment of the research question; (3) definition of strategies of search and inclusion and exclusion criteria; (4) search in the database and periodical portal; (5) analysis of the selected studies; and (6) presentation of knowledge synthesis ${ }^{18}$.

In order to present data related to the electrophysiological findings - specifically on semantic processing (i.e., N400 component) of children 0 to 6 years old - the leading question was: is there an electrophysiological activation pattern for the semantic processing in children 0 to 6 years old? Does this pattern change throughout the language development?

\section{Search procedure}

\section{First stage}

A search on the Health Virtual Library -Lilacs, Ibecs, MedCarib, Wholis and Adolec bases, Pubmed/Medline, Scopus, Web of Science bases and the periodical electronic library Scielo - Scientific Electronic Library Online was made with no period restriction, using descriptors (i.e., standardized terms defined by specialists) that were found after consulting the Health Science Descriptors - DeCS, or free language words related to the objective of the present study. It must be observed that this survey was carried out with the help 
of a professional librarian of the area who works in a Teaching and Research Unit.

Precisely, the descriptors/words used in the portuguese survey were: linguagem, comportamento verbal, desenvolvimento da linguagem, transtornos do desenvolvimento da linguagem, semântica, ERP e N400. For the search in English, the following descriptors/words were used: language, verbal behavior, language development, language development disorders, semantics, ERP, evoked potential N400 and N400.

\section{Criteria for the selection of articles}

The articles used in this review were obtained by February 2017 and the inclusion criteria were: (a) research articles - original and complete about the specified topic; (b) publications in Portuguese, Spanish or English.

We excluded the papers: (a) replicated in different databases; (b) of review; (c) and the ones that did not report about the N400 component.

\section{Second stage}

We also performed an analysis of the references in the selected articles on the first stage, in order to find another studies about the topic. When it occurred, the articles were attached to the list of papers analyzed in the review.

\section{LITERATURE REVIEW}

There were 127 articles in the database initially. We accomplished then an analysis through two researchers who reached a consensus that 15 studies of the first stage fulfilled all the criteria listed. As a result of the second stage, we included new studies. The results related to the search and analyses of the 24 articles are organized below (Figure 1).

Table 1 depicts the year of publication, the authors, the casuistry and the paradigm of the collected articles.

The authors of the present study decided to categorize the articles using the method proposed by Ruiz-Olabuénaga (2012) ${ }^{39}$ in order to have a qualitative discussion of the 24 articles selected. This method goes from thematic nuclei trying to find contiguity and matching among the different studies by grouping them in wide categories. Having established that, the studies were grouped in two thematic nuclei and two age ranges, namely, (a) typical children between zero and two years and eleven months; (b) children with risk of/and communication disorders aged between zero and two years and eleven months; (c) children showing a typical development aged between three and six years and eleven months; (d) and children with risk of/ and communication disorders aged between three and six years and eleven months.

The presentation of the studies followed the children's chronological age in ascending order.

\section{The N400 effect in children showing a typical development and aged between zero and two years and eleven months}

In this thematic, we shall present the ten studies that were found in the review process.

In the attempt of investigating the semantic process at 12 months old, researchers elaborated an image versus sound paradigm with coherent terms (real words) and incoherent terms (non-sense words) showed randomly 5 . The authors divided the children into two groups: low and high production of vocabulary. Only the high production of vocabulary group presented the $\mathrm{N} 400$ effect. Despite the presence of this effect, it was observed a delay at the latency and a short duration of the wave when compared to the one observed in older children and adults, and the authors have speculated that there is strong evidence of the relation between the language development and the functioning of neural mechanisms that generate the N400 effect. However, the absence of the N400 effect in children with low production of vocabulary was interpreted as a merely associative relation (between image and sound) regarding the brain maturation, and according to the authors it does not imply semantic processing.

In another study ${ }^{35}$, they used a task of hearing priming semantic of pairs of words in order to check if the words stored in the long term semantic memory are organized by semantic categories in children aged between 18 and 24 months old. In this regard, they showed pairs of related and independent stimuli, and the results revealed that children aged 18 months old and with a high vocabulary performance displayed the N400 effect as well as children aged 24 months old. It suggests that the advanced vocabulary skills can contribute for the organization of the developing semantic-lexical system.

One single study investigated the changes in the brain activity patterns related to the meaning of gestures and words in children aged 18 and 26 months old ${ }^{26}$. For the evaluation, they selected 22 objects associated with 


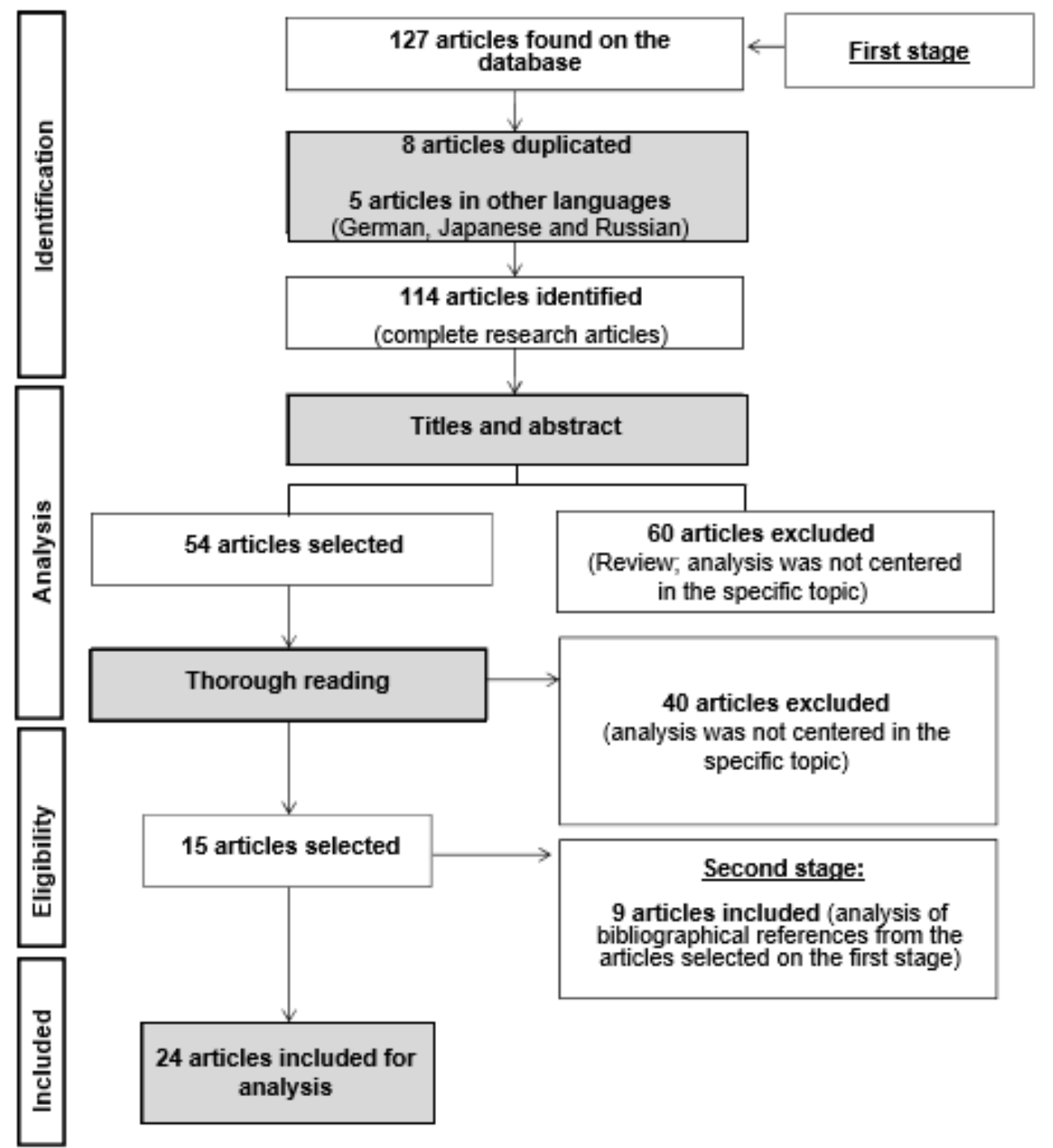

Note: Adapted from Moher, Liberati, Tetzlaff and Altamn (2009) ${ }^{19}$.

Figure 1. Selection process and results of the bibliographical survey

gestures and words, and the results suggested that gestures and words seem to share a similar processing neural system at early language acquisition stages (i.e., 18 months old) but they seem to divert at age 24 months old when words provide a stronger semantic context. Hence, gestures and words seem to take on diverging communicative functions.

Frierich and Friederici (2004) ${ }^{22}$ proposed to investigate if the $\mathrm{N} 400$ effect is present during language acquisition. In this regard, they used the image versus words paradigm in coherent and incoherent ways randomly. At 19 months old, children showed the N400 effect for incoherent way distributed through the scalp, while the left hemisphere seems to show a bigger activation in contrast to the adult one. While comparing children with high and low performance in comprehension tasks, children with low performance showed a subtle effect for semantic inconsistency in the left hemisphere and with a delayed latency. On the other hand, children with a high performance showed the effect for inconsistency at the same latency showed by the adults, despite the distribution in the scalp not corresponding exactly to the adults.

In this sense, in order to investigate the semantic processing in children aged 19 and 24 months old, they used a paradigm of hearing sentences with coherent and incoherent endings at random ${ }^{23}$. At 24 months old, there was an increased negativity (i.e., broader range) for incoherent stimuli and with centerparietal distribution; and at 19 months old, there was a similar response however with a broader distribution through the scalp. In general, the negativity started at 
Table 1. Summary of the information about the compiled articles

\begin{tabular}{|c|c|c|c|}
\hline Year & Authors & Casuistry* & Paradigm \\
\hline 1992 & Holcomb; Coffey; Neville ${ }^{16}$ & $\begin{array}{l}36 \text { individuals aged between } 5 \text { and } 26 \\
\text { years old }\end{array}$ & $\begin{array}{l}\text { Coherent and incoherent auditory } \\
\text { sentences }\end{array}$ \\
\hline 1996 & Juottonen; Revonsuo; Lang20 & $\begin{array}{l}36 \text { children aged between } 5 \text { years } 11 \\
\text { months old and } 11 \text { years } 5 \text { months old }\end{array}$ & $\begin{array}{l}\text { Coherent and incoherent auditory } \\
\text { sentences }\end{array}$ \\
\hline 1999 & $\begin{array}{l}\text { Byrne; Connolly; MacLean; Dooley; } \\
\text { Gordon; Beattie }\end{array}$ & $\begin{array}{l}56 \text { children aged between } 5 \text { and } 12 \\
\text { years old }\end{array}$ & $\begin{array}{l}\text { Image versus coherent/incoherent } \\
\text { words }\end{array}$ \\
\hline 2004 & Friedrich; Friederici22 & $\begin{array}{c}55 \text { children aged } 19 \text { months old and } 20 \\
\text { adults average aged } 23 \text { years } 7 \text { months } \\
\text { old }\end{array}$ & $\begin{array}{l}\text { Image versus coherent/incoherent } \\
\text { words }\end{array}$ \\
\hline 2005 & Friedrich; Friederici²3 & $\begin{array}{c}111 \text { children aged } 19 \text { and } 24 \text { months } \\
\text { old }\end{array}$ & $\begin{array}{l}\text { Coherent and incoherent auditory } \\
\text { sentences }\end{array}$ \\
\hline 2005 & Silva-Pereyra; Klarman; Lin; Kuhl24 & 19 children aged 30 months old & $\begin{array}{l}\text { Coherent and incoherent auditory } \\
\text { sentences }\end{array}$ \\
\hline 2005 & Silva-Pereyra;Rivera-Gaxiola;Kuhl² & 35 children aged 3 and 4 years old & $\begin{array}{l}\text { Coherent and incoherent auditory } \\
\text { sentences }\end{array}$ \\
\hline 2006 & $\begin{array}{l}\text { Torkildsen; Sannerud; Syversen; } \\
\text { Thormodsen; Simonsen; Moen et al. }{ }^{12}\end{array}$ & 27 children aged 20 months old & $\begin{array}{l}\text { Image versus coherent/incoherent } \\
\text { words }\end{array}$ \\
\hline 2006 & Friedrich; Friederici ${ }^{25}$ & 40 children aged 19 months old & $\begin{array}{l}\text { Image versus coherent/incoherent } \\
\text { words }\end{array}$ \\
\hline 2007 & Sheenan; Namy; Mills ${ }^{26}$ & 34 children aged 18 and 26 months old & $\begin{array}{l}\text { Image versus coherent/incoherent } \\
\text { gestures or words }\end{array}$ \\
\hline 2007 & $\begin{array}{c}\text { Torkildsen; Syversen; Simonsen; Moen; } \\
\text { Lindgren }{ }^{27}\end{array}$ & $\begin{array}{l}36 \text { children aged between } 20 \text { and } 24 \\
\text { months old }\end{array}$ & $\begin{array}{l}\text { Image versus coherent/incoherent } \\
\text { words }\end{array}$ \\
\hline 2008 & Torkildsen; Svangstu; Hansen; Smith²8 & 44 children aged 20 months old & $\begin{array}{l}\text { Image versus coherent/incoherent } \\
\text { words }\end{array}$ \\
\hline 2010 & Friedrich; Friederici5 ${ }^{5}$ & 52 children aged 12 months old & $\begin{array}{l}\text { Image versus coherent/incoherent } \\
\text { words }\end{array}$ \\
\hline 2010 & $\begin{array}{l}\text { McCleery; Ceponiene; Burner; } \\
\text { Townsend; Kinnear; Schreibman²9 }\end{array}$ & $\begin{array}{l}28 \text { children average aged } 5 \text { years } 8 \\
\text { months old }\end{array}$ & $\begin{array}{l}\text { Image versus coherent/incoherent } \\
\text { words/ambient sound }\end{array}$ \\
\hline 2011 & Schipke; Friederici; Oberecker ${ }^{30}$ & $\begin{array}{c}87 \text { children aged } 3 ; 4 ; \text { and } 6 \text { years } 6 \\
\text { months old }\end{array}$ & $\begin{array}{l}\text { Coherent and incoherent auditory } \\
\text { sentences }\end{array}$ \\
\hline 2011 & $\begin{array}{c}\text { Takahashi; Suzuki; Shibata; Fukumitsu; } \\
\text { Gyoba; Hagiwara et al. }{ }^{31}\end{array}$ & $\begin{array}{c}59 \text { children aged between } 4 \text { and } 5 \text { years } \\
\text { old }\end{array}$ & $\begin{array}{l}\text { Coherent and incoherent auditory } \\
\text { sentences }\end{array}$ \\
\hline 2011 & $\begin{array}{c}\text { Ojima; Matsuba-Kurita; Nakamura; } \\
\text { Hoshino; Hagiwara }\end{array}$ & $\begin{array}{c}350 \text { children aged between } 6 \text { and } 9 \\
\text { years old }\end{array}$ & $\begin{array}{l}\text { Image versus coherent/incoherent } \\
\text { words }\end{array}$ \\
\hline 2012 & Shipke; Knoll; Friederici; Oberecker ${ }^{15}$ & $\begin{array}{c}87 \text { children aged } 3 \text { and } 4 \text { years } 6 \\
\text { months old }\end{array}$ & Auditory sentences \\
\hline 2013 & Kuipers; Thierry ${ }^{33}$ & $\begin{array}{c}26 \text { children aged between } 2 \text { and } 3 \text { years } \\
\text { old }\end{array}$ & $\begin{array}{l}\text { Image versus coherent/incoherent } \\
\text { words }\end{array}$ \\
\hline 2013 & Weber-Fox; Wray; Arnold ${ }^{34}$ & $\begin{array}{c}54 \text { children aged between } 3 \text { and } 5 \text { years } \\
\text { old }\end{array}$ & $\begin{array}{l}\text { Coherent and incoherent auditory } \\
\text { sentences }\end{array}$ \\
\hline 2013 & Rämä; Sirri; Serres ${ }^{35}$ & $\begin{array}{l}43 \text { children aged 18, 23, and } 24 \\
\text { months old }\end{array}$ & $\begin{array}{c}\text { Pairs of words from similar or different } \\
\text { semantic categories }\end{array}$ \\
\hline 2014 & $\begin{array}{l}\text { Maitre; Henderson; Gogliotti; Pearson; } \\
\text { Simmos; Wang et al. }{ }^{36}\end{array}$ & $\begin{array}{c}16 \text { children aged between } 5 \text { and } 12 \\
\text { years old }\end{array}$ & $\begin{array}{l}\text { Image versus coherent/incoherent } \\
\text { words }\end{array}$ \\
\hline 2015 & Borgström; Torkildsen; Lindgren ${ }^{37}$ & $\begin{array}{c}70 \text { children aged between } 20 \text { and } 24 \\
\text { months old }\end{array}$ & $\begin{array}{l}\text { Image versus coherent/incoherent } \\
\text { words }\end{array}$ \\
\hline 2015 & Kuipers; Thierry ${ }^{38}$ & $\begin{array}{c}14 \text { children average aged } 29 \text { months } \\
\text { old and } 14 \text { children average aged } 32 \\
\text { months old }\end{array}$ & $\begin{array}{l}\text { Image versus coherent/incoherent } \\
\text { words }\end{array}$ \\
\hline
\end{tabular}

*Number of children and age in years/months 
the same time of the adults, however the effect lasted until $1200 \mathrm{~ms}$ - this could indicate a slower processing.

The objective of another study ${ }^{28}$ was to investigate the semantic processing after teaching the association between new words and images for children aged 20 months old and with high and low vocabulary performance. For the electrophysiological evaluation, the associations trained were violated and the associations of real words and images were added as control condition. The results showed there was an influence from the quantity of vocabulary in the mapping performance, i.e., as for new words the group with high performance related to the vocabulary showed the N400 effect for inconsistency of the words learned when the relationship taught was violated, and there was a broad distribution of the effect through the scalp. The low performance group related to the vocabulary did not show any difference between consistency and inconsistency, and the authors raised the hypothesis that there was no mapping or the mapping was not enough to elicit the N400 effect, probably because of the brain maturation. Regarding the real words, both groups showed the $\mathrm{N} 400$ effect for inconsistency with centered distribution at the center-parietal region; however, the effect was more right laterally at the low performance group. Thus, the results showed that only the children with high performance in relation to the vocabulary could establish stable connections between new words and referred ones.

Following this topic, Borgström and collaborators $(2015)^{37}$ a longitudinal investigation of the electrophysiological answers during a quick mapping in children between 20 and 24 months old. They used stimuli organized in ten independent sets: 3 words versus real objects and 3 pseudo-words versus new objects, and each one was showed at random way, and the stimuli sets were different at 20 and 24 months old. The size of the vocabulary related solely to the modulation of the N400 effect for pseudo-words showing a remarkable capacity development of quick mapping between 20 and 24 months old. In coherent stimuli, there was a difference of the activation pattern at 20 and 24 months old, i.e., at 20 months old there was no main effect but an interaction that indicated an inconsistency effect solely to real words; at 24 months old, however, the main effect appeared. These interactions indicated that as for the pseudo-words there was a bigger negativity for incoherent showings in all regions. In general, the children triplicated the productive vocabulary in four months demonstrating changes in the N400 effect, and children with high production of vocabulary showed a modulation of the $\mathrm{N} 400$ effect similar to the adults.

Torkildsen and collaborators (2006) ${ }^{12}$ investigated the effect of the semantic organization of long term memory for inconsistency answers from children aged 20 months old. In this regard, they used a task with image versus sound paradigm, in which each word had one of the three types of relation with the image content: (1) coherent - control condition; (2) - incoherent - intracategory, supra ordinary violation; or (3) incoherent - violation among categories. The children with high performance showed an inconsistency effect with a smaller latency, bigger range and a slightly right lateralization when compared to children with low performance in which the answer tend to have a left lateralization. Regarding the categories, the $\mathrm{N} 400$ effect was observed in a similar way in both incoherent conditions however with a smaller latency and bigger range for the condition among categories when compared to the intra-category condition, which suggests that the children were able to discriminate between two basic level words in the same supra ordinary category. In this sense, such data highlight that the $\mathrm{N} 400$ effect seems to be sensitive to inconsistency under semantic organization of the mental lexis.

The image versus semantically coherent and incoherent words paradigm was also used with the intention of comparing the electrophysiological indicators of attention and semantic integration in bilingual and monolingual children aged two and three years old ${ }^{38}$. Through the semantic integration analysis, the N400 effect did not differ among the groups, and it suggests that bilingualism does not affect the oral comprehension.

Having the purpose of investigating the electrophysiological pattern of children aged 30 months old, Silva Pereyra et al. (2005) ${ }^{24}$ used a task with 53 semantically coherent sentences and 53 incoherent sentences. The result found was compared to a previous study with children aged 36 and 48 months old². The formation of the negative wave at 30 months old showed the same pattern from children aged 36 and 48 months old, i.e., it was significantly bigger in relation to the semantically incoherent sentences and in previous electrode, and it suggests that the activation of these brain areas for the processing occurs early at the development stage. 


\section{The N400 effect in children showing risk of communication disorder and aged between zero and two years and eleven months}

Friedrich and Friederici (2006) ${ }^{25}$ investigated if the N400 occurrence at 19 months old is associated to the language skills of children with and without risk of Specific Language Impairment. They used a task composed of coherent and incoherent words (i.e., pseudo-words and not words) versus object images. The children from the control group showed a bigger restricted range in the frontal region of the left hemisphere for coherent words and bigger range and wide distribution for incoherent words. The children from the risk group showed an answer with a bigger range only for coherent words (i.e., they did not show the N400 effect for incoherent words) in the frontal region of both hemisphere as well as in the central and temporal right hemisphere. These results suggested that the N400 effect shows up earlier in children without the risk factor at the language skills development.

In the same perspective, Torkildsen and collaborators $(2007)^{27}$ proposed that the investigation of the lexical-semantic ignition effects on children with and without risk of developing dyslexia (positive family background) between 20 and 24 months old. For this purpose, they used tasks divided by: coherent in control condition (i,e., the word matches the image); incoherent with violation inside the category (i,e., the word does not match the image, but they are from the same semantic category); and incoherent with violation among categories (i.e., the word does not match the image and they are from different semantic categories). The children at risk of developing dyslexia showed in general a negative answer to the control condition and violation among categories. These conditions elicited the N400 effect with bigger range in relation to the violation among categories condition.

\section{The $\mathrm{N} 400$ effect on preschool children showing a typical development}

This topic, in turn, gathers nine studies found about children with typical development.

The N400 effect associated to the changes in the pupil sizes in monolingual and bilingual children aged 2 and 3 years old was investigated in a word-image correspondent paradigm ${ }^{33}$. For the evaluation, they showed the children a spoken word and after $850 \mathrm{~ms}$ they showed a coherent - or not - image to the one showed previously. As a result, both groups showed equivalent electrophysiological answers for the N400 effect, i.e., incoherent stimuli generated a deflection with a bigger range when compared to the coherent stimuli. Regarding the result about the pupil dilation, both groups showed differences: bilingual children showed a similar pattern to the adults (i.e., bigger dilation for the incoherent condition); and monolingual children showed equivalent answers for both types of stimuli. In this sense, bilingual children showed a positive correlation between the pupil size and the $\mathrm{N} 400$ effect range for the incoherent condition, while monolingual children showed a negative correlation. According to the authors, monolingual and bilingual children showed similar proficiency to match corresponding images and words, but they differ regarding the attention given to the task, where bilingual children gave more attention to the unexpected stimuli, and which would take to a more efficient processing.

Having the purpose of investigating the difference and the time related to the ERPs induced by morph syntactic sentences and sentences that are semantically anomalous, they used sentences composed of words found on the MacArthur Inventory database and 34 verbs $^{2}$. They built 53 coherent sentences; another 53 incoherent sentences were built and the last word was changed in order to create an inconsistency to the verb; the sentences were presented randomly. At age three years old, we observed negative waves with a bigger range for sentences that are semantically incoherent. The first negativity started at $400 \mathrm{~ms}$ and peaked by $500 \mathrm{~ms}$, and it was significantly bigger for the sentences that are semantically incoherent; the second negativity started at $550 \mathrm{~ms}$ and peaked by $650 \mathrm{~ms}$; and the last negativity peaked at $800 \mathrm{~ms}$ and ended around $1000 \mathrm{~ms}$. At age four years old, we can observe the two negative waves showed at three years old, however, the first wave was evident in this age range and the second negativity was substantial in all scalps.

Schipke, Friederici and Oberecker (2011) proposed to investigate processing strategies during the syntactic-thematic violations of typical children aged three years old, four years six months old and six years old. For the evaluation, they built 96 sentences of which: 24 were correct for the noun-object relation; 24 were correct for the object-noun relation; 24 with double incorrect nominative; 24 with double incorrect accusative. The three groups showed negativity for the double nominative violation; at the 4 year-old group, the negativity had its left lateralization on the parietal region; and at the 6 year-old group there was 
also negativity. Although three year-old children could detect morph syntactic violations, they did not identify the syntactic and thematic process (N400). The four year-old children started developing the thematic skill parietal negativity on the left (N400) - where the latency decreased with age. At the six year-old group, the N400 was observed and it reflect the difficulty on the thematic integration. Thus, the authors concluded that the N400 effect can appear in children, but it depends on the linguistic structures studied and highly likely on the child's domain over the structures used.

In a subsequent study ${ }^{15}$ with the same population, the authors investigated the development in the processing of marking structures of cases and arguments, that is, they investigated the potential elicited in responses to the initial object compare to the initial noun of sentences in German including transitive verbs and nominal sentences. For the evaluation, they built 48 sentences of which 24 showed initial noun condition and the other 24 showed the initial object condition. The results demonstrated that three-yearold children are insensitive to detecting the information about case marking; four-year-old six-month children did not show differences while processing both conditions. Six-year-old children showed the same negativity pattern found in adults, peaked by its latency, but it was not so extended and focal as it is in adults. Therefore, six-year-old children present the processing at the beginning of the sentence in a similar way adults do, but not for the rest of the sentence.

Takahashi and collaborators (2011) ${ }^{31}$ examined the effect of exposure to non-native language (i.e., English) over the ERPs of preschool Japanese children aged between four and five years old. The four-year-old children were exposed to English for 15 minutes a day while the five-year-old children were exposed for 45 minutes a day. For the evaluation of this exposure effect, they used 88 sentences in Japanese with coherent and incoherent endings. The five-year-old children showed differences both in the latency and distribution of the $\mathrm{N} 400$ effect through the scalp when compared to the control group and the four-year-old group; they could not find the effect on the four-year-old group. Thus, the authors concluded that the processing latency, duration and distribution were vulnerable to the exposure time to English.

In the same perspective, another study investigated the effect of non-native language and the quantity of exposure over learning in children aged between six and nine years old. This research was made in longitudinal scenario for three years ${ }^{32}$. For the evaluation, they used 80 basic level English words and 80 Japanese words in sessions with 320 trials and images presentation; each image was presented with coherent and incoherent context at pseudorandom order. The results showed that when the exposure time was controlled, the age of the first exposure led to a higher proficiency in English and bigger range of the $\mathrm{N} 400$ effect; a longer exposure time led to a better proficiency in English and bigger ranges of the $\mathrm{N} 400$ effect, regardless the age of the first exposure. These data highlighted the importance of exposure quantity in learning a non-native language and it casts doubt about the belief that begin learning a non-native language earlier produces better results.

In a cross-sectional study ${ }^{16}$ with individuals aged between 5 and 26 years old, the purpose was to outline developmental changes in the processing of coherent and incoherent sentences. The children aged 5 and 6 years old were evaluated with a hearing task version, while the other ones were evaluated with a written task through reading. Children aged 5 and 6 years old showed the N400 effect only at incoherent sentences, as well as older children and adults. It was also noted that the N400 latency and range decreased with age: 5 -year-old children showed latency around $620 \mathrm{~ms}$; teenagers around $500 \mathrm{~ms}$; and adults around $400 \mathrm{~ms}$.

Juottonen, Revuso and Lang (1996) ${ }^{20}$ investigated the presence of the $\mathrm{N} 400$ effect in children aged between 5 and 11 years old and adults through stimuli that require semantic processing, that is, they used 200 sentences of which 100 were coherent and 100 were incoherent - they were presented randomly. As a result, they found out that $\mathrm{N} 400$ effect was different in children and adults. In children the peak occurred much later for coherent and incoherent sentences (between 500 and $600 \mathrm{~ms}$ ) and it had a right lateralization on the frontal and parietal regions; in adults, the peak occurred solely to incoherent sentences (between 400 and $500 \mathrm{~ms}$ ) and it did not show any asymmetry between the hemispheres. Consequently, the same pattern was found in previous studies about the N400 effect.

Lastly, a study with this thematic proposed to test the validity of a computed passive hearing task in order to access the receptive vocabulary of typical children aged between 5 and 12 years old ${ }^{21}$. They selected 80 images from the PPVT-R test that formed 160 stimuli, that is, for each image there were two hearing stimuli - coherent and incoherent - presented randomly. The results pointed out that at the 5-6 age group the N400 component was defined between 400 and $800 \mathrm{~ms}$, and 
it occurred a range increase for incoherent regardless the brain sites. Such data suggested that in this neurodevelopmental stage children are able (accurately) to process information but it is not efficient because it is distributed through the scalp. Therefore, such data offered a first positive step in order to use these types of tasks in children with expressive language and motor control impairments.

\section{The $\mathbf{N} 400$ effect on preschool children at risk of/ and communication disorders}

Considering this topic, the semantic processing skills evaluated through the $\mathrm{N} 400$ effect were investigated in children aged between 3 and 5 years old who have stuttering-like disfluencies and its controls ${ }^{34}$. For the evaluation, spoken sentences (i.e., stimuli) accompanied the visual presentation of five cartoon episodes in which two sceneries were created for each episode, and the coherent and incoherent stimuli were showed randomly and balanced among the participants. The groups showed an increase on the N400 effect range upon semantic alterations, however there was no statically significant different among the groups. Soon, the authors state the possibility of access process and lexical integration less efficient for children that stutter which could decrease the semantic processing efficiency.

Another study ${ }^{29}$ had the purpose of investigating the verbal and non-verbal semantic processing of highfunction (and their pairs) autistic children aged between 4 and 7 years old through ERPs. In this regard, it was used an image versus sound paradigm (the same used in previous studies) in which children observed up to two sets of 108 trials (54 coherent, 54 incoherent) in each condition - ambient words or sounds versus images. It was not observed differences among the groups in the number of trials and only typical children showed differences at the $\mathrm{N} 400$ range between coherent and incoherent words, that is, high-function autistic children did not show any detection rate of semantic inconsistency ( $\mathrm{N} 400$ effect) in response to incoherent words versus images. However, this group showed the N400 effect in response to incoherent ambient sounds as well as the group with typical development.

A single study researched the $\mathrm{N} 400$ effect in population diagnosed with Cerebral Palsy ${ }^{36}$, and it had the objective of investigating the possibility of registering changes at the cerebral activation patterns after motor intervention. For such evaluation, the authors used as base the task proposed by Byrne and collaborators (1999), that is, a passive receptive task of coherent and incoherent image-word correspondence in three moments: before the intervention, right after the intervention and six months following the intervention. The results showed difference at the coherent and incoherent stimuli activation patterns in the studied population. Regarding the injury contralateral hemisphere, the inconsistency range was bigger and similar in the three evaluation moments. In the injury ipsilateral hemisphere, there were differences between the incoherent range increase right after the intervention and six-month follow-up. Thus, such data suggest that ERP methodology is appropriate for measuring the cortical functions of children with language and motor impairments, and it allows us to observe the effects of motor intervention.

Looking at the revised articles with more detail, it was observed that most studies had the purpose of investigating and describing the electrophysiological pattern of younger children in relation to the pattern found in older children and adults in semantic processing tasks. The variability of experimental employed tasks (e.g., pairs of words, image versus sound, relations education, and sentences) showed many investigation alternatives in this perspective. However, the variability of procedures can affect the control degree and the data reliability.

In a typical developmental thread, it was observed that 12-month-old children who have a high vocabulary production showed the $\mathrm{N} 400$ effect with a delay in the latency and decreased duration of the wave when compared to the one observed in older children and adults 5 ; at 19 and 24 months old incoherent stimuli caused a bigger range that started at the same time it does in adults, however, with extended effect in both age groups ${ }^{22,23,25}$; at 20 months old, children with low and high vocabulary production differed in the mapping performance of new words but not for real words ${ }^{28}$; at 30 months old ${ }^{24}$ and from 3 to 6 years old ${ }^{2,16}$, children showed a negative effect for semantically anomalous words, similar to the patterns reported in older children and adults.

Regarding the hemisphere issue, at 19 months old typical children showed a restricted activation for the left hemisphere frontal region for coherent words and wide distribution for incoherent words ${ }^{25}$; at 20 month old, the effect tended to have a left lateralization in children with low language perfomance ${ }^{28}$; and at 3 and 4 years old the $\mathrm{N} 400$ effect occurred on the left hemisphere ${ }^{16}$, 
however the author reported that at 4 years old this effect had a left lateralization ${ }^{30}$.

The studies suggest that the size of the vocabulary influences the presence and absence of the $\mathrm{N} 400$ effect and that the right lateralization is dependent on spoken language production skills, suggesting that such distribution could reflect maturation of the lexical-semantic processing ${ }^{5,12,22,28,35}$.

In the population at risk or with communication disorders, it was observed that at 19 months old children at risk of developing SLI showed a bigger range of the $\mathrm{N} 400$ effect only for coherent words ${ }^{25}$; at 20 and 24 months old, control and violation between categories stimuli caused an N400 effect with a bigger range in relation to the violation between categories condition in children at risk of developing Dislexy ${ }^{27}$; from 3 to 5 years old children with stuttering-like disfluencies showed bigger range and latency of the N400 effect upon semantic alterations ${ }^{34}$; high-function autistic children aged between 4 and 7 years old did not show the N400 effect in the inconsistency between words and images, only for inconsistency of ambient sounds ${ }^{29}$; and children with cerebral palsy showed difference in the activation pattern after motor intervention ${ }^{36}$.

Regarding the hemispheric activation, children at risk of developing SLI showed activation of the frontal region in both hemispheres, as well as on the central and temporal right hemisphere ${ }^{25}$; and in children with cerebral palsy the injury contralateral hemisphere showed bigger and similar range to the inconsistency during the evaluations ${ }^{36}$.

In general, the joint analysis of the results showed that despite having different objectives, types of experimental tasks and degrees of language skills (i.e., typical development or communication disorders), age was a relevant factor while defining the presence or absence of the $\mathrm{N} 400$ effect and its lateralization. When it occurred, the general finding indicates that the latency and range of the wave decrease with age.

In conclusion, it is believed that one of the limitations of the current review article refers to a still restricted number of researches about the topic. It is assumed that this result is due to recent advancements in the language electrophysiological studies and to the diversity of descriptors used in the studies, as there is no standardization of descriptors - which would help researchers frame their works into a specific topic and facilitate the topic recovery.

\section{FINAL CONSIDERATIONS}

This study consisted of a literature review about the semantic processing in children 0 to 6 years of age by analyzing the N400 data.

The identification of the neural correlates of the cognitive-behavior processes involved in the spoken language in relation to the contextual control is an important aspect for the understanding of specific aspects of the language development. Thus, it is assumed that studies in this field can contribute not only for a more detailed analysis and understanding of the mechanisms that are involved in the human linguistic behavior but also for the production of knowledge about the development of useful technologies in order to evaluate and understand the performance of the language components in children with communication disorders.

For further studies, it is strongly recommended and an important step for the field the development of a default protocol in order to investigate the semantic processing through data provided by the $\mathrm{N} 400$ effect in different populations.

\section{ACKNOWLEDGMENTS}

To Denise Giacheti Gillio, Librarian at the Hospital for Rehabilitation of Craniofacial Anomalies (HRAC/ USP), for her assistance and cooperation in the data collection.

\section{REFERENCES}

1. Bates E, Thal D, Janowsky JS. Early language development and its neural correlates. In: Rapin I, Segalowitz S (eds.) Handbook of Neuropsychology, Child Neurology. Amsterdam: Elsevier; 1992. p. 69-110.

2. Silva-Pereyra J, Rivera-Gaxiola M, Kuhl PK. An event-related brain potential study of sentence comprehension in preschoolers: semantic and morphosyntactic processing. Cogn. brain res. 2005;23(2):247-58.

3. Werker JF, Lalonde C. Cross-language speech perception: Initial capabilities and developmental change. Dev. psychol. 1988;24(5):672-83.

4. Friedrich $M$, Friederici AD. Neurophysiological correlates of online word learning in 14-month-old infants. Neuro Report. 2008;19(18):1757-62.

5. Friedrich $M$, Friederici AD. Maturing brain mechanisms and developing behavioral language skills. Brain lang. 2010;114(2):66-71. 
6. Berger $\mathrm{H}$. Über das elektrenkephalogramm des menschen. Eur. arch. psychiatry. clin. neurosci. 1929;87(1):527-70.

7. Kutas M, Federmeier KD. Electrophysiology reveals semantic memory use in language comprehension. Trends cogn. sci. 2000;4(12):463-70.

8. Kutas M, Federmeier KD. Thirty years and counting: finding meaning in the $\mathrm{N} 400$ component of the event-related brain potential (ERP). Ann. rev. Psychol. 2011;62(1):621-47.

9. Blackwood DH, Muir WJ. Cognitive brain potentials and their application. Br. j. psychiatr. 1990;157(9):96-101.

10. Stöhr M, Kraus R. Eletroencefalografia clínica (EEG). In: Stöhr M, Kraus R (orgs). Introdução à neurofisiologia clínica: EMG - EEG - potenciais. São Paulo: Editora Santos; 2009. p. 47-59.

11. Kutas M, Hillyard SA. Reading senseless sentences: Brain potentials reflect semantic incongruity. Sci. 1980;207(4427):203-05.

12. Torkildsen JK, Sannerud T, Syversen G, Thormodsen R, Simonsen HG, Moen I et al. Semantic organization of basic-level words in 20-month-olds: An ERP study. J. neurol. 2006;19(6):431-54.

13. Sabisch B, Hahne A, Glass E, Suchodoletz W, Friederici AD. Lexical-semantic processes in children with specific language impairment. Neuroreport. 2006;17(14):1511-14.

14. Pinheiro AP, Galdo-Álvarez S, Sampaio A, Niznikiewicz M, Gonçalves OF. Electrophysiological correlates of semantic processing in Williams syndrome. Res. dev. disabil. 2010;31(6):1412-25.

15. Schipke CS, Knoll LJ, Friederici AD, Oberecker R. Preschool children's interpretation of object-initial sentences: Neural correlates of their behavioral performance. Dev. Sci. 2012;15(6):762-74.

16. Holcomb PJ, Coffey AS, Neville HJ. Visual and auditory sentence processing: A developmental analysis using event-related brain potentials. Dev. neuropsychol. 1992;8(2-3):203-41.

17. Cummings $A$, Čeponienè R. Verbal and nonverbal semantic processing in children with developmental language impairment. Neuropsychologia. 2010;48(1):77-85.

18. Mendes KDS, Silveira RCCP, Galvão CM. Revisão integrativa: método de pesquisa para a incorporação de evidências na saúde e na enfermagem. Texto \& contexto enferm. 2008;17(4):758-64.
19. Moher D, Liberati A, Tetzlaff J, Altman DG. Preferred reporting items for systematic reviews and meta-analyses: the PRISMA statement. PLoS med. 2009;6(7):e1000097.

20. Juottonen K, Revonsuo A, Lang H. Dissimilar age influences on two ERP waveforms (LPC and N400) reflecting semantic context effect. Cogn. brain res. 1996;4(2):99-107.

21. Byrne JM, Connolly JF, MacLean SE, Dooley JM, Gordon KE, Beattie TL. Brain activity and language assessment using event-related potentials: Development of a clinical protocol. Dev. med. child. neurol. 1999;41(11):740-47.

22. Friedrich M, Friederici AD. N400-like semantic incongruity effect in 19-month-olds: Processing known words in picture contexts. J. cogn. neurosci. 2004;16(8):1465-77.

23. Friedrich M, Friederici AD. Semantic sentence processing reflected in the event-related potentials of one-and two-year-old children. Neuroreport. 2005;16(16):1801-04.

24. Silva-Pereyra JFS, Klarman L, Lin LJF, Kuhl PK. Sentence processing in 30-month-old children: an event-related potential study. Neuroreport. 2005;16(6): 645-48.

25. Friedrich M, Friederici AD. Early N400 development and later language acquisition. Psychophysiology. 2006;43(1):1-12.

26. Sheehan EA, Namy LL, Mills DL. Developmental changes in neural activity to familiar words and gestures. Brain lang. 2007;101(3):246-59.

27. Torkildsen JK, Syversen G, Simonsen HG, Moen I, Lindgren M. Brain responses to lexical-semantic priming in children at-risk for dyslexia. Brain lang. 2007;102(3):243-61.

28. Torkildsen JK, Svangstu JM, Hansen HF, Smith L, Simonsen HG, Moen I et al. Productive vocabulary size predicts event-related potential correlates of fast mapping in 20-month-olds. J. cogn. neurosci. 2008;20(7):1266-82.

29. McCleery JP, Ceponiene R, Burner KM, Townsend J, Kinnear M, Schreibman L. Neural correlates of verbal and nonverbal semantic integration in children with autism spectrum disorders. J. child psychol. psychiatry allied discipl. 2010;51(3):277-86.

30. Schipke CS, Friederici AD, Oberecker R. Brain responses to case-marking violations in German preschool children. Neuroreport. 2011;22(16):850-54. 
31. Takahashi J, Suzuki Y, Shibata H, Fukumitsu Y, Gyoba J, Hagiwara $\mathrm{H}$ et al. Effects of non-native language exposure on the semantic processing of native language in preschool children. Neurosci. Res. 2011;69(3):246-51.

32. Ojima S, Matsuba-Kurita $\mathrm{H}$, Nakamura N, Hoshino $\mathrm{T}$, Hagiwara $\mathrm{H}$. Age and amount of exposure to a foreign language during childhood: Behavioral and ERP data on the semantic comprehension of spoken English by Japanese children. Neurosci. res. 2011;70(2):197-205.

33. Kuipers JR, Thierry G. ERP-pupil size correlations reveal how bilingualism enhances cognitive flexibility. Cortex. 2013;49(10):2853-860.

34. Weber-Fox C, Wray AH, Arnold H. Early childhood stuttering and electrophysiological indices of language processing. J. fluency disord. 2013;38(2):206-21.

35. Rämä P, Sirri L, Serres J. Development of lexical-semantic language system: N400 priming effect for spoken words in 18-and 24-month old children. Brain lang. 2013;125(1):1-10.

36. Maitre NL, Henderson G, Gogliotti S, Pearson J, Simmons $A$, Wang $L$ et al. Feasibility of eventrelated potential methodology to evaluate changes in cortical processing after rehabilitation in children with cerebral palsy: A pilot study. J. clin. exp. neuropsychol. 2014;36(7):669-79.

37. Borgström K, Torkildsen JK, Lindgren M. Substantial gains in word learning ability between 20 and 24 months: A longitudinal ERP study. Brain lang. 2015;149(1):33-45.

38. Kuipers JR, Thierry G. Bilingualism and increased attention to speech: Evidence from event-related potentials. Brain lang. 2015;149(1):27-32.

39. Ruiz-Olabuénaga Jl. Metodología de la investigación cualitativa. 5a ed. Bilbao: Universidad de Deusto; 2012.

\section{ERRATUM}

In the title of this article, "N400 analysis of semantic processing in children aged zero to six years: a literature review", with DOI number: 10.1590/19820216201719513517, published in the journal Revista Cefac 19(5):690-701, on page 690:

\section{Where it was:}

$\mathrm{N} 400$ analysis of semantic processing in children aged zero to six years: a literature review

Read:

Semantic processing in children 0 to 6 years of age: an N400 analysis 